\title{
Kajian Kuat Mekanis Alkali-Activated Mortar (AAM)
}

\author{
Muhammad Sofyan'; Abdul Rokhman'; Dicki Dian Purnama ${ }^{3}$; Ade Okvianti Irlan ${ }^{4}$ \\ 1, 2, 3 Institut Teknologi PLN \\ ${ }^{4}$ Universitas Trisakti \\ 1'm.sofyan@itpln.ac.id
}

\begin{abstract}
Mortar is one material that has diverse benefits in building construction. So far, conventional mortar is used as a plaster or coating material in buildings. The main binding material for mortars is basically still relying on cement. Utilization of coal in steam power plants is still one of the main streams as supporting electricity needs. The buildup of coal combustion products such as fly ash and bottom ash has the potential to disrupt the stability of the environmental ecosystem. AlkaliActivated mortar by relying on an alkaline activator solution reacted with pozzolanic materials such as fly ash, Ground Granulated Blast Furnace Slag (GGBFS), Palm Oil Fuel Ash (POFA) and others can be one solution to reduce the accumulation of fly-ash waste. In some previous research studies, ideally the quality control of Alkali Activated mortar can be explored in its mechanical strength such as compressive strength and flexural strength. In this article, we will review how the mechanical strength of several types of Alkali-Activated Mortar. From the studies to be discussed, a conclusion will be drawn based on mechanical testing data which can ultimately provide recommendations on how the mechanical performance of Alkali-Activated mortar.
\end{abstract}

Keywords: Alkali-Activated mortar, Fly-Ash, Mechanical Strength, GGBFS

\section{ABSTRAK}

Mortar salah satu material yang memiliki manfaat yang beraneka ragam dalam konstruksi bangunan. Sejauh ini, mortar konvensional digunakan sebagai bahan plester atau coating pada bangunan. Bahan pengikat utama mortar pada dasarnya masih mengandalkan semen. Pemanfaatan Batubara pada pembangkit listrik tenaga uap masih menjadi salah satu arus utama sebagai pendukung kebutuhan energi listrik. Penumpukan hasil sisa pembakaran batu bara seperti fly ash dan bottom ash berpotensi mengganggu stabilitas Ekosistem lingkungan. Alkali-Activated mortar dengan mengandalkan larutan alkali activator yang direaksikan dengan material pozzolanic seperti fly ash, Ground Granulated Blast Furnace Slag (GGBFS), Palm Oil Fuel Ash (POFA)ldan lain-lain dapat menjadi salah satu solusi dalam mengurangi limbah fly-ash yang menumpuk. Dalam beberapa riset riset terdahulu idealnya kontrol mutu dari Alkali Activated mortar dapat ditinjiau pada kekuatan mekanisnya seperti kuat tekan dan lentur. Dalam artikel ini akan ditinjau bagaimana kekuatan mekanis pada beberapa jenis Alkali-Activated Mortar. Dari studi-studi yang akan dibahas tersebut akan ditarik sebuah kesimpulan berdasarkan data-data pengujian mekanis yan pada akhirnya dapat memberi rekomendasi tentang bagaimana performa mekanis pada Alkali-Activated mortar.

Kata kunci: Alkali-Activated mortar, Fly-Ash, GGBFS, POFA, Kekuatan Mekanis 


\section{KILAT}

Vol. 10, No. 1, April 2021, P-ISSN 2089-1245, E-ISSN 2655-4925

DOI: https://doi.org/10.33322/kilat.v10i1.1114

\section{PENDAHULUAN}

Penggunaan material beton dalam konstruksi bangunan masih menjadi yang terdepan. Perkembangan Teknologi Beton berlangsung sangat cepat [1]. Semen adalah bahan utama pembuatan beton, Dalam proses pembuatan satu ton Semen Portland dapat menghabiskan sekitar $100 \mathrm{kWh}$ dan melepas 1.0 ton emisi $\mathrm{CO}^{2} \mathrm{ke}$ atmosfer [2]. Industri semen menjadi salah satu penghasil gas rumah kaca. sekitar 1 ton $\mathrm{CO}_{2}$ dihasilkan dan 2,5ton bahan termasuk bahan bakar dan bahan mentah lainnya dikonsumsi untuk setiap satu ton produksi semen Portland (OPC) [3ziyad kuba, 4-8].

Oleh karena itu, material alternatif perlu dikembangkan untuk mengurangi eksploitasi yang berlebih pada semen portland. Salah satu alternatif yang digunakan saat ini sebagai bahan subtitusi semen Portland adalah Fly Ash [9]. Secara umum ada fly ash terdiri dari dua tipe, yaitu tipe C dan tipe F. Fly Ash Tipe C mengandung minimal 50\% zat yang bersifat pozolanic [9]. Dibandingkan tipe F, Fly Ash tipe $\mathrm{C}$ mengandung kalsium yang lebih tinggi. (Gooma)

Mortar sebagai material konstriksi telah banyak dibahas oleh para penelti dari segi kelayakan dan prospek aplikasi mortar geopolimer sebagai bahan subtitusi yang tepat untuk mortar konvensional yang berbasis semen Portland [10.11-15].Geopolimer memainkan peran penting sebagai bahan pengikat yang tidak konvensional untuk memproduksi beton [10,15-18]. Beberapa penelitian [19-22] menunjukkan geopolimer memiliki perilaku berbeda dibandingkan dengan OPC, mendaur ulang limbah yang melimpah dengan biaya rendah serta ramahan lingkungan dalam rangka mengurangi emisi Gas rumah kaca.

Selama beberapa dekade, studi mengenai material konstruksi yang ramah lingkungan atau lebih dikenal dengan istilah green material telah dikembangkan oleh Banyak peneliti berfokus pada perilaku mekanis dan fisis mortar geopolimer/Alkali Activated mortar. Tujuan khusus dari artikel ini adalah untuk menyajikan perkembangan yang Berkenaan dengan sifat fisis mekanis dan mikrostrukturnya

\section{METODE}

Pengikatan Awal dan Akhir AAM adalah diukur dengan menggunakan jarum Vicat mengacu pada ASTM C807-13 [23]. Pengaturan waktu awal diukur dari waktu pencampuran FA dengan Larutan Alkali hingga penetrasi jarum berdiameter $2 \mathrm{~mm}$ tadi sama mencapai $10 \mathrm{~mm}$, sedangkan waktu pengaturan akhir ditentukan kapan tidak ada penetrasi yang signifikan. Workability mortar diuji sesuai ASTM C1437-15 [24]. Workability diukur dengan menempatkan dua lapisan mortar di dalam kerucut standar kemudian mengangkat kerucut dari mortar kemudian menjatuhkan meja sebanyak 25 kali dalam 15 detik. The melaporkan kemampuan kerja adalah rata-rata dari empat pengukuran diagonal. Kekuatan tekan campuran mortar ditentukan pada usia 7 hari menurut ASTM C109-16a [25].

\section{HASIL DAN PEMBAHASAN}

\subsection{Pozzolanic Material}

Ada beberapa Material Pozzolan yang dapat dimanfaatkan sebagai bahan pembuatan Alkaline-Activated Mortar seperti yang ditunjukkan pada tabel 1.

Tabel 1. Material Pozzolanic pembentuk AAM

\begin{tabular}{|c|c|c|}
\hline Klasifikasi & Material dasar & Singkatan \\
\hline Limbah Industri & Fly Ash [26,27] & FA \\
\cline { 2 - 3 } & Bottom Ash [28] & BA \\
\hline
\end{tabular}




\begin{tabular}{|c|c|c|}
\hline \multirow{2}{*}{} & Palm Oil Fuel Ash [29] & POFA \\
\cline { 2 - 3 } & Volcanic Ash [30] & VA \\
\cline { 2 - 3 } & Rice Husk Ash [31] & RHA \\
\hline Limbah Industri & $\begin{array}{c}\text { Ground Granulated blast } \\
\text { Furnace Slag [32] }\end{array}$ & GGBFS \\
\hline Limbah Industri & Metakaolin [33] & - \\
\cline { 2 - 3 } & Clay [34] & - \\
\hline
\end{tabular}

Beberapa faktor seperti Fase kaca, morfologi partikel, kehalusan, struktur mineral, kimia komposisi kimia bahan penyusun memiliki pengaruh yang signifikan terhadap aktivitas terbentuknya senyawa aluminosilikat [35]. Alkali Aktivator yang dapat digunakan ialah natrium silikat $\left(\mathrm{Na}_{2} \mathrm{SiO}_{3}\right)$, natrium hidroksida, dan potassium hydroxide $(\mathrm{NaOH}$ and $\mathrm{KOH})$ [36].

\subsection{Workability dan Kuat Tekan AAM}

Workability merupakan ukuran untuk menilai apakah sebuah campuran mortar dapat diaduk dengan mudah pada saat pencetakan benda uji. Pengadukan yang sulit akan membuat pekerjaan di lapangan akan mendapatkan kendala. Pada tahun 2018 Kuba et al.[3] melakukan studi wrokability AAM dengan berbagai variasi perbandingan GBFS:FA:POFA untuk tiga jenis alkali-aktivator seperti disajikan pada gambar 1 .

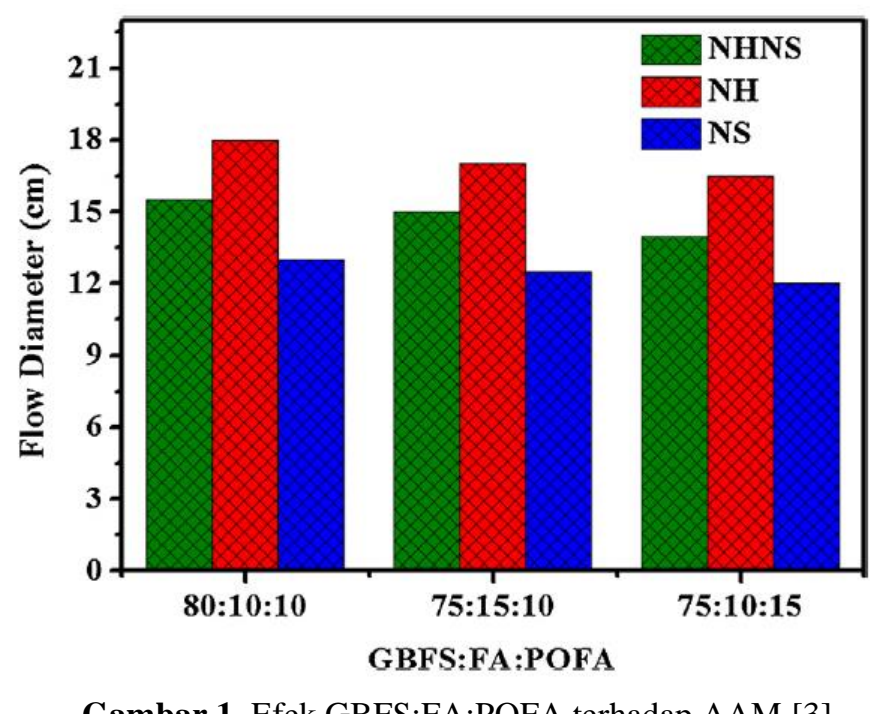

Gambar 1. Efek GBFS:FA:POFA terhadap AAM [3]

Pada gambar 1 terlihat bahwa pengurangan Konten GBFS dan peningkatan POFA di konten FA tetap (10\%) menyebabkan mengurangi kemampuan kerja GPM terlepas dari jenis larutan alkali (NHNS, NH dan NS). Namun, sifat FA dipengaruhi pada kemampuan kerja campuran geopolimer yang di set pada angka $15 \%$ FA.

Selain workability, kekuatan tekan mortar menjadi ukuran kualitas dari mortar, kuat tekan yang tinggi akan lebih handal dalam menerima tegangan aksial. beberapa faktor yang dapat berdampak pada kuat tekan adalah rasio $\mathrm{SiO}_{2} / \mathrm{N}_{2} \mathrm{O}$ dan rasio air / FA [37]. Selanjutnya dengan meningkatkan rasio molar $\mathrm{SiO} 2$ / N2O pada kuat tekan mortar hasilnya tidak jauh berbeda dengan Rasio Na2SiO3 / NaOH. Seperti yang disajikan pada Gambar 13, kekuatan tekan menurun diikuti 


\section{KILAT}

Vol. 10, No. 1, April 2021, P-ISSN 2089-1245, E-ISSN 2655-4925

DOI: https://doi.org/10.33322/kilat.v10i1.1114

dengan peningkatan rasio molar $\mathrm{Na} 2 \mathrm{SiO} 3$ / $\mathrm{NaOH}$ adalah 1, sedangkan kekuatan tekan meningkat dengan peningkatan rasio molar ketika rasio $\mathrm{Na} 2 \mathrm{SiO} 3 / \mathrm{NaOH}$ adalah 1,5 [38].

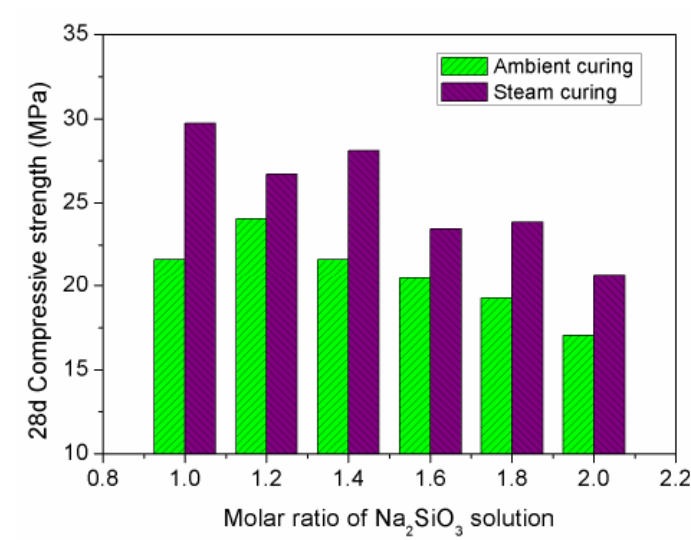

(a) $\mathrm{Na}, \mathrm{SiO}_{3} / \mathrm{NaOH}$ ratio=1

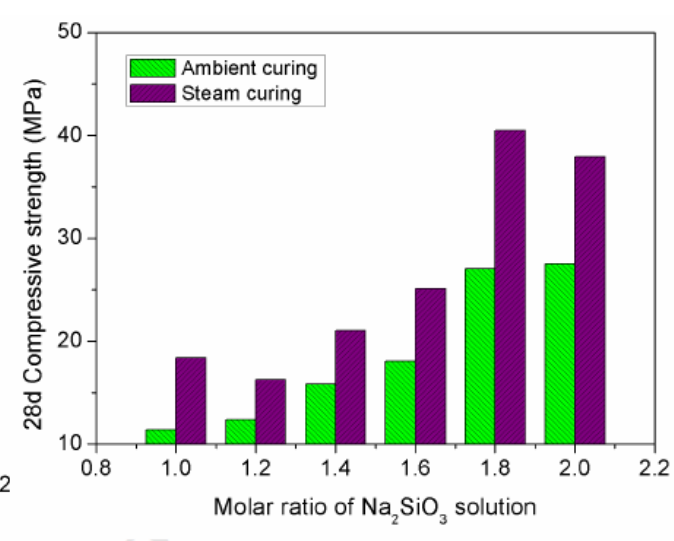

(b) $\mathrm{Na}_{2} \mathrm{SiO}_{3} / \mathrm{NaOH}$ ratio=1.5

Gambar 2. Rasio Molar Alkali Aktivator Terhadap Kuat Tekan [39]

Faktor lain yang dapat berkontribusi terhadap tingginya kekutan tekan adalah umur dari benda uji. Berdasarkan sebuah studi yang dilakukan oleh Hussein et al [39] yang menginvestigasi perilaku mekanis AAM dengan bahan pozzolan GGBFS dan POFA menunjukkan bahwa, kekuatan tekan semakin meningkat diikuti dengan bertambahnya umur benda uji. Pada Gambar 3 terlihat bahwa kekuatan tekan AAM yang menggunakan GGBFS dan POFA meningkat hingga pada usia 360 hari.

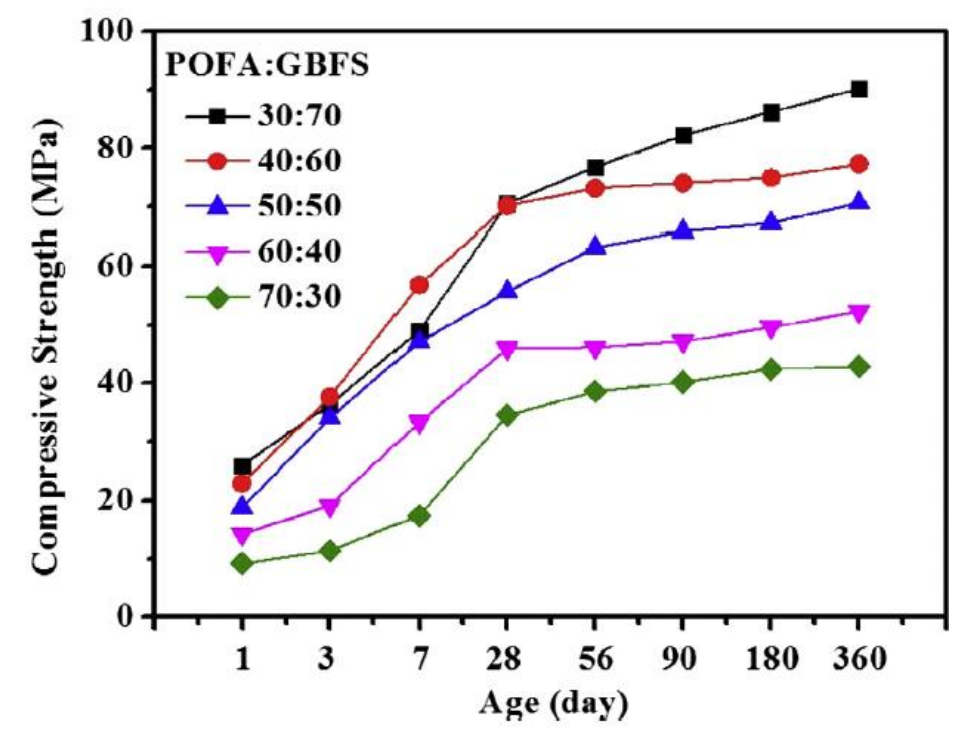

Gambar 3. Kuat tekan AAM dengan POFA/ GBFS terhadap usia benda uji [39] 


\section{KESIMPULAN DAN SARAN}

Dengan menentukan rasio molaritas larutan aktivator 1.5 pada AAM yang menggunakan GGBFS dan POFA dapat meningkatkan salah satu kekuatan mekanis material AAM yaitu kuat tekan. Selain itu, kekuatan tekan dari AAM dapat terus meningkat hingga usia 360 hari. Kekuatan menurun drastis jika rasio molaritas alkali aktivator yang digunakan adalah 1 .

\section{UCAPAN TERIMA KASIH}

Ucapan Terima Kasih Sebesar-besarnya kami haturkan kepada Institut Teknologi PLN/YPK PLN yang mendanai penelitian dan luaran penelitian yang peneliti telah susun. Secara Khusus Penulis/Peneliti juga mengucapkan terima kasih sebesar besarnya kepada LPPM-IT PLN dan Fakultas Teknologi Infrastruktur Dan Kewilayahan yang telah mendukung penuh dan memfasilitasi penelitian ini.

\section{DAFTAR PUSTAKA}

[1] M. Sofyan, B. Wicaksono, and A. O. Irlan, "Effect of Combination of Steel Fibre and Silica Fume on the Mechanical Strength of Concrete," IOP Conf. Ser. Mater. Sci. Eng., vol. 771, p. 012048, Mar. 2020, doi: 10.1088/1757-899x/771/1/012048.

[2] Temuujin, J., Minjigmaa, A., Davaabal, B., Bayarzul, U., Ankhtuya, A., Jadambaa, T., MacKenzie, K.J.D., 2014. Utilization of radioactive high-calcium Mongolian flyash for the preparation of alkali-activated geopolymers for safe use as construction materials. Ceram. Int. 40 (10, Part B), 16475-16483.

[3] Z. Kubba et al., "Impact of curing temperatures and alkaline activators on compressive strength and porosity of ternary blended geopolymer mortars," Case Stud. Constr. Mater., vol. 9, p. e00205, 2018, doi: 10.1016/j.cscm.2018.e00205.

[4] V. Malhotra, Introduction: sustainable development and concrete technology, Concr. Int. (2002) 24.

[5] G.F. Huseien, J. Mirza, M. Ismail, S. Ghoshal, A.A. Hussein, Geopolymer mortars as sustainable repair material: a comprehensive review, Renew. Sustain. Energy Rev. 80 (2017) 54-74.

[6] S.A. Zareei, F. Ameri, F. Dorostkar, M. Ahmadi, Rice Husk Ash as a Partial Replacement of Cement in High Strength Concrete Containing Micro Silica: Evaluating Durability and Mechanical Properties. Case Studies in Construction Materials, 7(2017) , pp. 73-81.

[7] R. Manjunath, M.C. Narasimhan, An experimental investigation on self-compacting alkali activated slag concrete mixes, J. Build. Eng. 17 (2018) 1-12.

[8] M.A. Asaad, M. Ismail, M.M. Tahir, G.F. Huseien, P.B. Raja, Y.P. Asmara, Enhanced corrosion resistance of reinforced concrete: role of emerging ecofriendly Elaeis guineensis/silver nanoparticles inhibitor, Constr. Build. Mater. 188 (2018) 555-568.

[9] E. Gomaa, S. Sargon, C. Kashosi, and M. ElGawady, "Fresh properties and compressive strength of high calcium alkali activated fly ash mortar," J. King Saud Univ. - Eng. Sci., vol. 29, no. 4, pp. 356-364, 2017, doi: 10.1016/j.jksues.2017.06.001.

[10] P. Zhang, Y. Zheng, K. Wang, and J. Zhang, "A review on properties of fresh and hardened geopolymer mortar," Compos. Part B Eng., vol. 152, pp. 79-95, 2018, doi: 10.1016/j.compositesb.2018.06.031.

[11] W. Yodsudjai, P. Suwanvitaya, W. Pikulprayong, B. Taweesappaiboon, Testing of geopolymer mortar properties for use as a repair material, Ceramic Transaction 215 (2010) 325-334. 


\section{KILAT}

Vol. 10, No. 1, April 2021, P-ISSN 2089-1245, E-ISSN 2655-4925

DOI: https://doi.org/10.33322/kilat.v10i1.1114

[12] W. Wazien A.Z., M.M.A.B. Abdullah, R.A. Razak, M.R. Rozainy M.A.Z., M.F.M. Tahir,K. Hussin, Potential of geopolymer mortar as concrete repairing materials, Materials Science Forum 857 (2016) 382-387.

[13] Y.S.D. Satya, E. Saputra, M. Olivia, Performance of blended fly ash (FA) and palm oil fuel ash (POFA) geopolymer mortar in acidic peat environment, Materials Science Forum 841 (2016) 8

[14] Z. Abdollahnejad, F. Pacheco-Torgal, J.B. Aguiar, C. Jesus, Durability performance of fly ash based one-part geopolymer mortars, Key Engineering Materials 634 (2015) 113-120.

[15] F. Pacheco-Torgal, J. Castro-Gomes, S. Jalali, Adhesion characterization of tungsten mine waste geopolymeric binder. Influence of OPC concrete substrate surface treatment, Constr. Build. Mater. 22 (2008) 154-161.

[16] T. Phoo-ngernkham, P. Chindaprasirt, V. Sata, S. Hanjitsuwan, S. Hatanaka, The effect of adding nano-SiO2 and nano-Al2O3 on properties of high calcium fly ash geopolymer cured at ambient temperature, Mater. Des. 55 (2014) 58-65.

[17] J. Davidovits, Geopolymer Chemistry and Applications. Saint-Quentin, FR: Geopolymer Institute, 2008 ISBN 978-2-9514820-1-2.

[18] G.F. Huseiena, M. Ismaila, M. Tahirb, J. Mirzac, A. Husseina, N.H. Khalida, et al., Performance of sustainable alkali activated mortars containing solid waste ceramic powder, Chem. Eng. (2018) 63.

[19] K.-H. Yang, J.-K. Song, K.-I. Song, Assessment of CO 2 reduction of alkali-activated concrete, J. Clean. Prod. 39 (2013) 265-272.

[20] G.F. Huseien, J. Mirza, M. Ismail, M.W. Hussin, M. Arrifin, A. Hussein, The effect of sodium hydroxide molarity and other parameters on water absorption of geopolymer mortars, Indian J. Sci. Technol. (2016) 9.

[21] M. Hussin, M. Bhutta, M. Azreen, P. Ramadhansyah, J. Mirza, Performance of blended ash geopolymer concrete at elevated temperatures, Mater. Struct. 48 (2015) 709-720.

[22] G.F. Huseien, J. Mirza, M. Ismail, Effects of high volume ceramic binders on flexural strength of self-compacting geopolymer concrete, Adv. Sci. Lett. 24 (2018) 4097-4101.

[23] Standard Test Method for Time of Setting of Hydraulic Cement Mortar by Modified Vicat Needle (2013). ASTM International.

[24] Standard Test Method for Flow of Hydraulic Cement Mortar (2015). ASTM International.

[25] Standard Test Method for Compressive Strength of Hydraulic Cement Mortars (Using 2-in. or [50-mm] Cube Specimens) (2016). ASTM International.

[26] A. Fernandez-Jimenez, A. Palomo, Engineering properties of alkali-activated fly ash concrete, ACI Materials Journal 103 (2) (2006) 106-112.

[27] J.S.J. van Deventer, G.C. Lukey, H. Xu, Effect of curing temperature and silicate concentration on fly-ash-based geopolymerization, Industrial \& Engineering Chemistry Research 45 (2006) 3559-3568.

[28] S. Hanjitsuwan, T. Phoo-ngernkham, N. Damrongwiriyanupap, Comparative study using Portland cement and calcium carbide residue as a promoter in bottom ash geopolymer mortar, Construction and Building Materials 133 (2017) 128-134.

[29] M. Olivia, C. Wulandari, I.R. Sitompul, Study of fly ash (FA) and palm oil fuel ash (POFA) geopolymer mortar resistance in acidic peat environment, Materials Science Forum 841 (2016) 126132. 
[30] J.N.Y. Djobo, A. Elimbi, H.K. Tchakoute, S. Kumar, Mechanical properties and durability of volcanic ash based geopolymer mortars, Construction and Building Materials 124 (2016) 606-614.

[31] Y.Y. Kim, B. Lee, V. Saraswathy, S. Kwon, Strength and durability performance of alkaliactivated rice husk ash geopolymer mortar, The Scientific World Journal 2014 (2014) 1-11.

[32] T. Bakharev, J. Sanjayan, Y. Cheng, Alkali activation of Australian slag cements, Cement and Concrete Research 29 (1999) 113-120.

[33] M. Clausi, S.C. Tarantino, L.L. Magnani, M.P. Riccardi, C. Tedeschi, M. Zema, Metakaolin as a precursor of materials for application in Cultural Heritage: geopolymer-based mortars with ornamental stone aggregates, Applied Clay Science 132-133 (2016) 589-599.

[34] Z. Wang, H. Su, S. Zhao, N. Zhao, Influence of phase change material on mechanical and thermal properties of clay geopolymer mortar, Construction and Building Materials 120 (2016) 329-334.

[35] M. Sumesh, U.J. Alengaram, M.Z. Jumaat, K.H. Mo, M.F. Alnahhal, Incorporation of nanomaterials in cement composite and geopolymer based paste and mortar-A review, Construction and Building Materials 148 (2017) 62-84.

[36] S. Teewara, F. Mizi, Influence of OPC replacement and manufacturing procedures on the properties of self-cured geopolymer, Construction and Building Materials 73 (2014) 551561.

[37] A. Bhowmick, S. Ghosh, Effect of synthesizing parameters on workability and compressive strength of fly ash based geopolymer mortar, International Journal of Civil and Structural Engineering 3 (1) (2012) 168-177

[38] J. Thaarrini, V. Ramasamy, Feasibility studies on compressive strength of ground coal ash geopolymer mortar, Periodica Polytechnica Civil Engineering 59 (3) (2015) 373-379.

[39] G. F. Huseien et al., "Synergism between palm oil fuel ash and slag: Production of environmental-friendly alkali activated mortars with enhanced properties," Constr. Build. Mater., vol. 170, pp. 235-244, 2018, doi: 10.1016/j.conbuildmat.2018.03.031. 